University of Nebraska - Lincoln

DigitalCommons@University of Nebraska - Lincoln

"They Don't Even Know that We Exist": Exploring Sense of Belonging Within Sorority and Fraternity Communities for Latina/o

Members

Crystal Garcia

Follow this and additional works at: https://digitalcommons.unl.edu/cehsedadfacpub

Part of the Bilingual, Multilingual, and Multicultural Education Commons, and the Educational Administration and Supervision Commons

This Article is brought to you for free and open access by the Educational Administration, Department of at DigitalCommons@University of Nebraska - Lincoln. It has been accepted for inclusion in Faculty Publications in Educational Administration by an authorized administrator of DigitalCommons@University of Nebraska - Lincoln. 


\title{
“They Don't Even Know that We Exist": Exploring Sense of Belonging Within Sorority and Fraternity Communities for Latina/o Members
}

\author{
Crystal E. Garcia \\ Assistant Professor of Administration of Higher Education, Auburn University \\ Correspondence - Crystal E. Garcia, crystalgarcia@unl.edu
}

\begin{abstract}
In this qualitative, multiple-case study, I explored the perceptions of members of Latinx/a/o-based sororities and fraternities and their feelings of belonging within the greater fraternity and sorority life (FSL) community. Findings reflect the salience of race and privilege in participant experiences as individuals recognized their organizations as different worlds from sororities and fraternities within the National Panhellenic Council and Interfraternity Council. Critical Race Theory and LatCrit were used to examine the roles of race and racism within the FSL community while also underscoring the unique experiences of Latina/o FSL members from 2 large, predominantly White universities in the Midwest. Findings suggest implications for addressing inequity within FSL communities and recommendations for future research.
\end{abstract}

Studies have pointed to the positive role that campus subcultures, such as racial/ethnic- based student organizations, may play in Latinx/a/o college students' sense of belonging (Garcia, 2017; Gonzalez, 2002; Museus \& Quaye, 2009). Note that the term Latinx/a/o(s) is used here as a

Published in Journal of College Student Development, Volume 60, Number 3 (May-June 2019), pp. 319-336.

doi:10.1353/csd.2019.0029

Published by Johns Hopkins University Press. Used by permission. 
gender-inclusive term to refer to members of the Latino/Hispanic community, while Latina/o is used in reference to the women and men that participated in this study. I also use Latinx/a/o in reference to sororities and fraternities, though I recognize these organizations have largely excluded individuals who do not identify as women or men. Latinx/a/o sororities and fraternities are student organizations that serve a dual role as racial/ethnic-based organizations and also as part of the fraternity and sorority life (FSL) community (Muñoz \& Guardia, 2009). Thus, membership in these groups not only socially connects students on campus, but also affirms their racial/ethnic identities and provides a space in which students experience a sense of belonging (Garcia, 2017). Furthermore, findings of studies focused on Latinx/a/o sororities and fraternities in relation to persistence (Delgado-Guerrero \& Gloria, 2013) and forms of development such as ethnic identity (Guardia \& Evans, 2008) and leadership (Atkinson, Dean, \& Espino, 2010) underscore the important role these organizations play in the experiences of members as they navigate university cultures and develop a sense of belonging.

Extensive research has presented arguments for the benefits of a culturally diverse campus community (see Denson \& Chang, 2009) and the need for inclusive environments in which "students feel safe and comfortable engaging meaningfully across cultural, ethnic, racial, socioeconomic, gender, and sexual orientation differences" (Museus, 2008, p. 207). The need for inclusive environments also applies to FSL, which is reflected in the Council for the Advancement of Standards in Higher Education (CAS) Standards. The Standards for Fraternity and Sorority Advising assert the need for practice that "fosters communication and practices that enhance understanding of identity, culture, self-expression, and heritage; and promotes respect for commonalities and differences among people within their historical and cultural contexts" (CAS, 2015, p. 25).

FSL communities are made up of councils that represent particular groups of social sororities and fraternities. Depending on the sorority and fraternity chapters-local campus groups of a national or international sorority or fraternity - that are established on a campus, there are typically up to four councils overseeing them. When two or more chapters of the same affiliation exist on a campus, an oversight council is formed: the Interfraternity Council (IFC) for fraternities in the North American Interfraternity Conference (NIC, 2017), the National 
Panhellenic Council (NPC, 2014), the National Pan-Hellenic Council (NPHC; Ross, 2000), or the Multicultural Greek Council (MGC; Muñoz \& Guardia, 2009). Latinx/a/o, Asian American, and other culturally based and multicultural organizations are typically grouped together on college campuses under MGC.

Though the CAS Standards espouse the need for inclusive FSL communities, research has largely focused on student experiences within particular FSL councils as opposed to centering student experiences within the broader FSL community. Some work has provided insight to these dynamics regarding students' experiences and sense of inclusion within FSL through the perspectives of NPHC members (Ray, 2013) and Asian American women (Park, 2008). Findings from these studies as well as others have highlighted issues centered around race that adversely affect the extent to which Students of Color may feel a sense of belonging within the larger FSL community (Bourke, 2010; Cabrera, 2014; Park, 2014; Ray \& Rosow, 2012).

While these studies offer insight into these dynamics, the literature has yet to reveal the extent to which members of Latinx/a/o sororities and fraternities experience a sense of belonging within the greater FSL community at predominantly White institutions (PWIs). To further interrogate climates for equity and inclusion within these spaces, there is a need to explore students' perceptions of their belonging as members of multicultural organizations. I aimed to explore this gap by examining: (a) How do members of Latinx/a/o sororities and fraternities perceive the role of their MGC organizations within the greater FSL community? And, as a result, (b) How do members of Latinx/a/o sororities and fraternities perceive their sense of belonging in relation to the greater FSL community?

\section{Background}

\section{Historical Exclusion Within Fraternity and Sorority Life}

During the early 20th century many sororities and fraternities adopted exclusionary clauses, largely excluding Students of Color from membership (Torbenson, 2012). The historical exclusion of these populations from FSL led to the development of National Pan-Hellenic Council 
sororities and fraternities as well as Latinx/a/o, Asian American, and other culturally based and multicultural organizations (Muñoz \& Guardia, 2009; Torbenson, 2012). Even though NPC sororities and NIC fraternities removed exclusionary clauses from organizational guiding documents following the passage of Civil Rights legislation, racial discrimination and exclusion have continued within FSL (Hughey, 2009). Many examples of racially charged behaviors can be found in news stories, including reports of "parties with racially insensitive themes or White supremacist overtones, mock 'slave auctions,' and numerous accounts of White fraternity members dressing in 'blackface' for parties and other social gatherings" (Hughey, 2009, p. 245). Owens Patton (2008) addressed the proliferation of blackface in Southern White fraternities, arguing this form of racism was perpetuated by "the preservation of White hegemonic patriarchal power” (p. 151).

\section{Race and Racism Within FSL Communities}

Although researchers have conducted extensive work focused on the role of FSL in college student experiences, few studies address ways race and racism play a role within these communities. What research does exist has illustrated that while the development of MGC and NPHC sororities and fraternities has provided alternative communities for students who do not feel welcomed by sororities and fraternities within NPC or NIC, examples of ways racism and segregation still persist within the greater FSL community have been documented (Asel, Seifert, \& Pascarella, 2009; Cabrera, 2014; Park, 2008, 2014; Ray, 2013). For instance, Cabrera (2014) argued that FSL is a prime example of how "white supremacy is reified in higher education, ... because students have the explicit ability to select members, frequently excluding people of color" (p. 32). Cabrera's qualitative study, which focused on the experiences of 12 White college men, half of whom were members of fraternities, provided evidence for this statement, showing that fraternities served as racially segregated spaces in which White participants lacked interactions with racially diverse others, yet participants "did not see this as problematic" (p. 50). Furthermore, fraternity members often espoused ethnic victimization and a "heightened awareness of 'reverse racism'" (p. 48).

Cabrera's (2014) findings were also mirrored in Ray's (2013) ethnography of the experiences of 52 White and Black fraternity men at a large, 
PWI. Ray found that because the White fraternity members had their own fraternity houses, they were able to "include desirable groups ... and exclude others, like racial/ethnic minorities" (p. 328). Furthermore, interactions among members of the IFC and NPHC fraternities were "extremely limited" (p. 328). In fact, some White IFC fraternity members did not even know NPHC fraternities existed, and only three members could name even one NPHC fraternity, while all Black NPHC fraternity members could name at least three IFC fraternities. Findings from other studies have also pointed to ways White privilege has played a role in the disparate treatment of NPHC and IFC fraternity men (Bourke, 2010; Ray \& Rosow, 2012).

Park's (2008) study focused on the experiences and perspectives of Asian American women in relation to the sorority community within a PWI. Park's findings point to ways students minimize the role of race in FSL. While the participants described ways that race affected the sorority system, including experiencing "racial otherness" and reporting that Women of Color were often not accepted in the more "prestigious houses," participants still asserted that "race was basically irrelevant to the system" (p. 114) and rationalized these differences with alternative explanations such as an individual lack of fit and the overall lack of diversity within the university. One member even asserted that the ethnic sororities and fraternities were "more discriminatory" (p. 121) than IFC or NPC, aligning with the ethnic victimization and reverse racism that Cabrera's (2014) participants claimed to experience.

\section{FSL and Cross-Racial Interactions}

Several researchers have examined the role of FSL in cross-racial interactions and intercultural competence. For instance, results from a study by Asel et al. (2009) of membership in sororities and fraternities show that when first-year members were compared to nonaffiliated peers, membership was found to have a significant negative relationship with interactions with diverse others. Similarly, Park's (2014) study suggests that involvement in FSL has a significant and negative relationship with interracial friendship. Yet, in contrast to the findings of Asel et al. and Park, other studies have pointed to a different or, rather, muddled picture of this issue. For instance, Martin, Parker, Pascarella, and Blechschmidt's (2015) examination of the role of fraternity and sorority membership on 
intercultural competence showed that membership did not have a significant effect on the development of intercultural competence over the college experience. Harris Combs, Stewart, and Sonnett's (2017) quantitative examination of racial affiliation preferences for college students at a Southern university showed that FSL affiliation had a significant positive relationship with same-race preferences for White women, but not for White men.

\section{Theoretical frameworks}

My aim was to bring to light the experiences of members of Latinx/a/o sororities and fraternities within the greater FSL community at PWIs using Critical Race Theory (CRT) and LatCrit lenses. CRT and LatCrit are complementary critical theories that have been used in conjunction with one another in educational research (Delgado Bernal, 2002; Solorzano \& Yosso, 2001). Considering the historical role of race and racism within FSL, I used CRT to interrogate ways race came into play within the greater FSL community, while using LatCrit to bring to light the unique experiences of Latinx/a/o FSL members. As Ladson-Billings (1998) explained: "The 'voice' component of CRT provides a way to communicate the experience and realities of the oppressed, a first step in understanding the complexities of racism and beginning a process of judicial redress" (p. 14).

LatCrit is grounded in tenets similar to CRT, but it additionally centers Latinx/a/o experiences, particularly "issues such as language, immigration, ethnicity, culture, identity, phenotype, and sexuality" (Delgado Bernal, 2002, p. 108). I remained cognizant of these nuances while primarily focusing on the five tenets that form the basis of CRT: "counter-storytelling; the permanence of racism; Whiteness as property; interest conversion; and the critique of liberalism" (Hiraldo, 2010, p. 54). CRT's first tenet, counter-storytelling, serves to give voice to individuals from marginalized populations. The second tenet, the permanence of racism, asserts the pervasive nature of racism as part of US society, "privileging White individuals over People of Color in most areas of life, including education" (Hiraldo, 2010, p. 55). The third tenet asserts the role of whiteness as property, which entails "the right of possession, the right to use and enjoyment, the right to disposition, 
and the right of exclusion" (Hiraldo, 2010, p. 55). Thus, Hiraldo (2010) asserted that whiteness is not only something individuals can have, use, and enjoy, but also that it can be used as a tool to advantage the individual and exclude others from those advantages. This tenet was salient in relation to the experiences of FSL members, because of the historical role of race within FSL in terms of who is included and who is excluded from these communities.

The fourth tenet, interest conversion, recognizes that "Whites have been the primary beneficiaries of Civil Rights legislation" (Ladson-Billings, 1998, p. 12). Affirmative action is an example of interest conversion in that White women have disproportionately benefitted from these policies (Ladson- Billings, 1998). Finally, CRT's fifth tenet, "critique of liberalism, stems from the ideas of color-blindedness, the neutrality of the law, and equal opportunity for all" (p. 56). Hiraldo argued that these perspectives assume the guise of equity, yet they are damaging to People of Color and allow "people to ignore racist policies that perpetuate social inequity" (p. 56). While culturally based sororities and fraternities serve students in important ways, the literature shows that these organizations are often not treated as equal to NPC and IFC chapters.

I also used Strayhorn's (2012) definition of sense of belonging: "students' perceived social support on campus, a feeling or sensation of connectedness, the experience of mattering or feeling cared about, accepted, respected, valued by, and important to the group (e.g., campus community) or others on campus (e.g., faculty, peers)" (p. 3). Furthermore, although this study was not focused on campus climate, dimensions of campus climate as described by Hurtado, Alvarez, Guillermo-Wann, Cuellar, and Arellano (2012) in the Multicontextual Model for Diverse Learning Environments (MMDLE) offer important considerations for FSL. At the institutional level, the historical dimension includes ways political and sociohistorical developments influence climate; the compositional dimension refers to the demographic makeup; the organizational dimension includes rules and regulations that govern institutional behavior; the psychological dimension entails individual perceptions and feelings; and the behavioral dimension includes interactions (Hurtado et al., 2012, p. 46). These dimensions were considered at the organizational level rather than the institutional level for this study. 


\section{Method}

This work was drawn from a larger study that examined the role of involvement in Latinx/a/o sororities and fraternities in how students developed and made meaning of their sense of belonging within PWIs. As participants discussed their experiences, racialized occurrences within the FSL community became a salient component of their reflections. This article highlights these findings using CRT and LatCrit theoretical perspectives.

I adopted a qualitative, multiple-case study approach (Merriam, 2001) to gain a more complex understanding of Latinx/a/o sorority and fraternity members' experiences. A case study is "an intensive, holistic description and analysis of a single, bounded unit" (Merriam, 2001, p. 194); a multiple-case study examines multiple cases to more fully understand the phenomenon of interest (Stake, 2006). A case is a "single entity" and can be an individual, a group, or even an institution; a case's defining feature is that it must be "intrinsically bounded" (Merriam, 2001, p. 27). To establish bounds in this study, cases were defined as Latinx/a/o sorority and fraternity members, that is, the individuals were the unit of analysis. Defining cases as individuals was an ideal method to explore the phenomenon of interest: how students perceived the role of their MGC chapters and their sense of belonging within the greater FSL community.

\section{Participant Selection}

I recruited participants using a purposeful selection process (Maxwell, 2013), with particular attention paid to context. I sought out members from five Latinx/a/o sorority and fraternity chapters from two large, public, 4-year PWIs, classified as R1, in different Midwestern US states: Plains University and Clearview University (pseudonyms). Student body demographics were similar at the institutions. White students comprised approximately $71 \%$ of the enrollment at Plains and $75 \%$ at Clearview. Latinx/a/o students made up approximately $5 \%$ of enrollment at both institutions. Nearly $17 \%$ of the undergraduate student population at Clearview and just over 20\% at Plains were involved in FSL. Plains had nearly 50 NPC and IFC, 7 NPHC, and approximately 10 MGC chapters. Clearview had nearly 40 NPC and IFC, 4 NPHC, and 4 MGC chapters. Ultimately, a total of 14 participants completed all phases of the project, 
Table 1. Participant Demographics

\begin{tabular}{|c|c|c|c|c|c|}
\hline Pseudonym & Chapter & Semester & $\begin{array}{l}\text { Age } \\
\text { (Years) }\end{array}$ & Race/Ethnicity & Major \\
\hline \multicolumn{6}{|c|}{ Plains University } \\
\hline Christina & Kappa Beta & 3 & 19 & Mexican & Apparel Design \\
\hline Davina & Kappa Beta & 3 & 19 & Mexican & Civil Engineering \\
\hline Nine & Kappa Beta & 7 & 21 & Latina & Psychology \\
\hline Paloma & Kappa Beta & 3 & 19 & Mexican & Kinesiology \& Health \\
\hline Delta & Nu Sigma & 7 & 25 & Hispanic/Latino & Mechanical Engineering \\
\hline Romeo & $\mathrm{Nu}$ Sigma & 5 & 20 & Hispanic & Civil Engineering \\
\hline Fernando & Omega Iota & 5 & 20 & Hispanic & Mechanical Engineering \\
\hline Hector & Omega Iota & 3 & 19 & Mexican American & Computer Engineering \\
\hline Juan & Omega Iota & 7 & 21 & Mexican American & Environmental Science \\
\hline \multicolumn{6}{|c|}{ Clearview University } \\
\hline Karla & Pi Delta & 3 & 19 & Mexican & Biochemistry \\
\hline Lori & Pi Delta & 5 & 20 & Hispanic & Nutrition \& Exercise Science \\
\hline Participant01 & Pi Delta & 7 & 21 & Latina & Human Development \& Family Science \\
\hline Omi & Pi Delta & 5 & 20 & Mexican American & Elementary \& Special Education \\
\hline Luis & Zeta Alpha & 7 & 21 & Latino & Latin American / Global Studies \\
\hline
\end{tabular}

Note. University and chapter names are pseudonyms.

including 6 Latino fraternity members and 8 Latina sorority members. All participants selected their own pseudonyms (including Participant01), and I assigned a pseudonym to each chapter. Table 1 provides additional participant demographics.

\section{Data Collection}

Participants completed demographics surveys and engaged in three individual interviews, each ranging from approximately 35 minutes to 1 hour and 10 minutes in length. Interviews relied on a semistructured approach, and in the second and third interviews I used photo elicitation (Clark-Ibáñez, 2004), which serves dual roles for the researcher and participant; while the researcher can use the photos to facilitate the interview conversation and draw details from the interviewee, the photos can also provide participants an alternate way to "communicate dimensions of their lives" (p. 1512). The focus of the larger study was on individual sense of belonging; thus, participants were asked to identify places where they belonged and places where they did not (on or 
off campus) and to bring pictures of these spaces to discuss during the second and third interviews. These photos were used to discuss what it was about those contexts that contributed to or detracted from their sense of belonging.

\section{Data Analysis}

To analyze these data, I conducted an inductive first cycle and second cycle coding process using code mapping on participant interview transcripts (Saldaña, 2016). Next, I constructed case analysis documents for each participant, which chronologically and thematically reconstructed their statements into stories of their experiences. I then moved from individual analysis to cross-case analysis using composite sequence analysis, which involves extracting "typical stories or scenarios from multiple individual cases to develop a collective network that represents their common and unique features in meaningful sequences and paths" (Miles, Huberman, \& Saldaña, 2014, p. 211). Using composite sequence analysis, I used the case analysis documents to identify common themes across participant experiences.

\section{Trustworthiness and Positionality}

I ensured the trustworthiness of this research in several ways. For one, I adopted a purposeful participant selection process by including participants who differed by institution, organization, and gender, which was useful in representing diverse perspectives and the possibility for discrepant evidence (Maxwell, 2013). Furthermore, using a multiple-case study design also contributed to this aim. Merriam (2001) explained: "The more cases included in a study, and the greater the variation across the cases, the more compelling an interpretation is likely to be" (p. 40). I also engaged in member checking, allowing participants to provide feedback regarding preliminary findings. Finally, while my subjectivity could not be completely removed from the research process (Maxwell, 2013), I exercised reflexivity and engaged in memoing (Saldaña, 2016) on my subjectivity and identity (Merriam \& Tisdell, 2016).

I identify as a multiracial Latina and White woman born and raised in Texas, a state with a substantial Latinx/a/o population. My racial identity gives me both insider and outsider perspectives on the educational 
experiences of Latinx/a/o students and plays an important role in how I perceive the world and my research. In some ways, being Latina gives me an insider perspective through shared cultural experiences with my participants, yet my experiences may also differ. For instance, I grew up in an English-speaking home and I do not speak Spanish fluently. In addition, when people see me or meet me for the first time, my phenotype causes many people not to recognize me as a Latina; therefore, I have never personally felt marginalized or discriminated against based on my racial identity. Through my experiences as a Latina first-generation college student, a member of an NPC sorority, and a student affairs administrator, I bring experiential knowledge to my research. I call attention to my positionality and insider/ outsider role because a foundation of critical research is "challenging power relations both in the world and in the research process itself" (Merriam \& Tisdell, 2016, p. 64). As a critical researcher, I must reflect on how these issues manifest themselves within participant experiences and the research setting.

\section{Findings}

Participants' reflections revealed four interconnected themes that explained how they perceived the roles of their sororities and fraternities as well as their individual sense of belonging in relation to the FSL community beyond MGC. The first theme, Different Worlds and Racial Divides, was reflective of the psychological dimension (Hurtado et al., 2012) as it characterized participants' perceptions of their sororities and fraternities as different worlds from the IFC and NPC organizations. The next two themes, Marginalization Within the FSL Community and Marginalization in the FSL Office, were indicative of the behavioral dimension (Hurtado et al., 2012) as they more specifically exemplified the ways participants' chapters were actively marginalized within the FSL community and by FSL campus professionals, which further contributed to their perception of these divides. In the fourth theme, Recognizing Multicultural Greek Organizations, participants discussed ways organizations were recognized and made visible on campus. 


\section{Different Worlds and Racial Divides}

All participants recognized a distinction between IFC and NPC sororities and fraternities - organizations that they referred to as "traditional Greek organizations" - and multicultural and NPHC sororities and fraternities, sometimes going so far as to describe them as "different worlds," as Christina said. Luis saw IFC and NPC organizations as being completely different from his fraternity in terms of "how they operate, their culture, everything."

Cultural and Organizational Differences. Because the MGC and NPHC organizations were culturally based, they fundamentally promoted ties to Latinx/a/o culture through initiatives that benefit the Latinx/a/o community and by connecting members to students that shared cultural backgrounds. As an extension, Juan also believed that members of Latinx/a/o sororities and fraternities showed an overall "greater racial awareness and advocate for issues" more than traditional sororities and fraternities did. He explained that members of the two types of organizations have "different views about everything. You know it comes with your ethnicity, it comes with your background." As part of a representation of their culture, members engaged in strolling and saluting, which are not part of NPC and IFC culture. Strolling is a tradition, adopted from NPHC organizations, that Paloma described as "party walking ... you're kind of doing dance moves or you're moving and you're also throwing your sign up and stuff like that to show that you're proud of your organization." Some particular occasions where they saluted or strolled included new member showcases, NPHC new line reveals (called a probate), or stroll-off competitions.

Beyond the focus on culture, three primary differences surfaced in participant reflections: (a) Latinx/a/o sororities and fraternities were much smaller in size than IFC and NPC chapters; (b) the chapters involved in this study did not own houses as most IFC and NPC chapters did; and (c) the cost of IFC and NPC membership was much greater than the cost of Latinx/a/o sorority and fraternity membership. Notably, the cost of membership affected the way participants viewed members of IFC and NPC organizations. This was illuminated by Karla: "I think for traditionals, it's mainly for rich, White people ... just because you have to pay thousands and thousands of dollars.... And I guess being in my 
sorority, the fees ... they're like less than $\$ 200$." Privilege, therefore, was a common theme in describing members of IFC and NPC, which participants recognized as being different from their own memberships. While some members reflected on aspects of cost and wealth in relation to membership in the FSL community, race was perhaps the most pervasive difference participants recognized among chapters.

Racial Disparities. For many participants, a lack of belonging within the FSL community as a whole primarily stemmed from racial disparities they recognized between the traditional sororities and fraternities and their own organizations. Hector thought there was some degree of "discrimination" among the councils in the FSL community: "like White sororities and White fraternities distancing away multicultural fraternities." This was ingrained in some members' perspectives before they made the decision to join FSL. Participant01, for instance, did not see much racial or ethnic diversity in the IFC and NPC chapters:

Usually they're all predominantly White. But then again I've never really interacted with them. So when you are a minority, more than likely you'll be told to look at multicultural fraternities and sororities.... In my sorority we pride ourselves in saying yeah we're Latina based, but we accept anybody from different racial backgrounds.

Participant01's choice of words in this statement, "more than likely you'll be told," points to a greater pattern of perpetuating racial exclusion and division within the FSL community. Even though NPC sororities did not openly acknowledge that membership was limited to White students, the FSL culture caused Participant01 to see this as the norm and as different from her sorority.

Participant01 was not alone in her perspective; all participants described traditional organizations as being predominantly White and often less inclusive than their own organizations. This was illuminated in Lori's rationale for joining a Latina sorority rather than an NPC organization, where the members "were all White. So it was like, 'How can I talk about my mom's papusas with you if you don't even know?'" whereas she could share her culture with members of her sorority. She reflected that if she joined an NPC sorority and they had parent days: "I can't bring 
my mom over there.... I would not feel comfortable.... Because she doesn't know English.... She's very Hispanic, and I feel like they would judge her. I could not have that—-them judging my mom." Lori's perception of how she and her mom would be treated by an NPC sorority was much different from her place in Pi Delta where "I feel like I actually belong." Lori did not feel as though she had to hide who she was around her sisters. Her mom had met a few of them already, but Lori would feel comfortable introducing all of her sisters to her mom because "we could bond, ... because we're Latinas we know how it is."

Lori's reflection underscored two essential points. First, her Latinabased sorority offered a space where she could belong and where she felt connected to others who shared cultural backgrounds with her. Second, regardless of the presence of other Latinas in NPC sororities, she saw these chapters as spaces in which her identity as a Latina would be marginalized or even ridiculed. While culturally based sororities and fraternities are intended to serve as spaces in which individuals can feel culturally connected to others, the notion of NPC and IFC chapters as exclusionary based on racial/ethnic identity points to systemic issues of racism within the FSL community.

The image of IFC and NPC chapters as unwelcoming to People of Color was again evident when participants were asked by the researcher to self-reflect on locations where they did not feel a sense of belonging (on or off campus). Without prompting, the FSL housing areas on campus were identified by 8 participants as spaces where they did not belong. Delta described one of these areas:

I don't know the proper term they call it, but I think it's Greek Row or Greek Street. ... They all have houses and ... it feels like an environment that you're not supposed to be there. Just because ... the majority of the population in that area is a different race than you, different background, so it's like you're a foreigner in that area.

Although Luis had to walk by the FSL housing area of campus "a lot," he had "no sense of belonging" there. He reflected that when he passes this area: "I will speed walk and definitely have my head down." Similarly, although Lori did not have to walk by the FSL houses every day, on occasions when she had, she would "just walk real quick." Lori added that she 
was worried that "they would look at me in a certain way or something."

This sense of discomfort expressed by the participants was sometimes a result of not seeing their racial or ethnic identities reflected in IFC and NPC chapters; at other times it was a result of participants' perceptions that their racial or cultural identity was not valued within those communities. Omi attributed her lack of belonging in the FSL housing area to the fact that "most of the fraternities are White-based.... I feel they would maybe treat us very differently ... because we're Hispanic, and most traditionals don't have Hispanic guys in there, so they really don't know much about our culture and what to say." While Omi never experienced any discriminatory situations on campus first-hand, hearing about another student's experience influenced the way she felt about the NPC and IFC organizations. She explained that a Black football player "went to a fraternity house and they were telling him like 'No, Black guys can't come in here' and [they] were just saying racist remarks to him." Hearing his story was significant to Omi:

Football is big here, he's a starter and everything. ... If that's how they treated a student athlete, man, I think they would treat me worse than that, since I'm just a student, not an athlete.... Hearing him say that made me think, "I don't think I can get near those places."

\section{Marginalization Within the FSL Community}

In addition to the ways that participants perceived divisions within the FSL community, there were also behavioral community norms that actively marginalized MGC chapters and reinforced these perceptions. The majority of the participants expressed that the campus community either did not understand the purpose of MGC organizations or did not even know they existed, and many believed it was also true that IFC and NPC organization members did not understand the purpose of these sororities and fraternities. Participant01 thought this was a problem because: "We do just as much as anybody, ... but we're not even seen." Feeling as though people did not even recognize the chapter was "frustrating at some points. ... When I'm like, 'Oh I'm part of Pi Delta,' and they're like, 'What is that?' 'Oh it's a multicultural sorority. 'Ok so what do you guys do?' And it's like, 'Just about everything everybody else 
does." Paloma did not "feel welcomed by [IFC and NPC chapters], because they don't know what the Multicultural Greek Council is. And like I guess our ideals or values or even process ... also they don't really reach out to [the] Multicultural Greek Council to get to know us." As a result: "I don't involve myself in that community."

Lack of Interaction. Given that there was largely a lack of awareness of the existence of MGC chapters within FSL, it was not surprising that there was a lack of interaction across councils. Participants often discussed the close relationships their chapters had with other MGC and NPHC chapters. Karla said: "Whenever they have an event, they always make sure to invite us, and we always make sure to invite them, just because we know they'll be there to support us because we're a small community." Participants made it clear that collaboration with or even interactions among IFC, NPC, and multicultural chapters were sparse or nonexistent. As Hector described it: "Most of the time those events are mostly within the Multicultural Greek Council to have all the MGC Greek orgs together. But like organizations from all four councils together? Not much." Hector went on to assert the role of race in this dynamic:

Multicultural Greek members are mostly going to stay in their own groups and distance themselves from the traditional fraternities and sororities because it's White dominated and White populated. And they don't feel the sense of belonging just being in all that; they see separation.

Similarly, Fernando explained that there were not really any collaborations or events that brought chapters in the different councils together unless "individual organizations reach out to another individual organization." Overall, he believed the sense of community among MGC and IFC and NPC organizations was relatively nonexistent:

I don't interact with many IFC orgs or [NPC]. ... There are times when the presidents of some IFC orgs do come to our cultural events. I don't know if it's because they're obligated to or what it is, but they do come.... Other than that, you don't see too much participation to try to understand what we are, who we are. 
Racially Driven Motives. The general lack of interaction or collaboration among members of the councils led several participants to have suspicions regarding the motives of IFC and NPC chapters that tried to be involved with MGC chapters. Fernando's experiences with IFC and NPC chapters led him to question whether an invitation to their houses would be genuine:

I would be willing to go, that's for sure, but then it's always stuck in the back of my head like I know there's going to be some of these people that actually speak negatively about me and people that look like me. But they just do it behind my back.

Ultimately he did not think his willingness to go would matter because "either way, it's not like they would ever invite our organizations."

Several members reflected on racialized experiences they had with IFC and NPC chapters that influenced their perceptions. For instance, Luis explained that his fraternity was weary of working with IFC chapters: "Because then we feel like the traditional fraternity is just using us for their point system ... or to like make it seem that they're not racist or not discriminating." Luis explained that a few years ago, an IFC fraternity wanted to cosponsor with his fraternity on a "burrito bash ... to make it seem like, 'Well what we're doing is not culturally insensitive, it's not racist because Zeta Alpha is cosponsoring with us.' And I know that happens in our university."

Another example was offered by Delta, who thought that in terms of "other White sororities and fraternities, it feels that we're the odd ones out, it feels that we're not included." One particular experience he recalled was when his chapter was involved in Greek Week. His fraternity-Omega Iota-was grouped together with one Latina sorority and several IFC and NPC chapters. One of the members of Omega Iota received an e-mail inviting them to a football watch party at one of the IFC fraternity's houses and requested an RSVP. Delta admitted that the member of Omega Iota "that received that e-mail didn't reply back"; however he and one of his brothers decided to attend, and when they knocked on the door, one of the fraternity members answered and "asked who we were.... We informed him we were from Omega Iota and were there due to an e-mail we received. Yet, they had no idea who 
we were." Even though "we weren't even invited to walk in," Delta and his brother stepped into the entryway because "it was cold." Delta described that they were having the event, and in "the other room you could see the TV, you could see people eating," but they were not even asked if they would like a drink. The member that answered the door asked for their phone numbers and said: "We'll figure out what's going on and get back to you guys." So Delta and his brother left, but the member never called. Afterward Delta "followed up with the Latina organization" and discovered that "two of their sisters went, but they ran into the same problem ... so they left."

After the incident Delta and his brothers no longer participated in Greek Week. Delta said the "fraternity's president never reached out to apologize, never said anything." Much later, during an all-FSL presidents' meeting, they planned to discuss the incident along with an NPHC member's complaint that "one of his members, who was African American, was called the 'N word' on his way back to campus coming back from supporting one of the White Greek letter organization's events." Following the meeting: "The director of Greek [Life] said he was going to work on facilitating with multicultural student affairs a workshop or lecture that was specifically going to talk about diversity and inclusion"; however Delta noted the incident occurred "over a year ago, so nothing ever really happened."

A Hope for More. While collaborative efforts or even interactions among members of the councils were not common, some of the participants expressed a desire for a stronger FSL community. Some of these participants hoped that these changes would stem from the FSL office. For example, despite Luis's perceptions of the way things had been within the FSL community at Clearview University, he thought that things could be better:

I know a chapter brother who's from another university, and he's always telling me stories about how their Greek environment is more inclusive and how they have all these great connections with all the traditional sororities and the traditional fraternities.

Although his fraternity had not established a relationship with other IFC or NPC chapters, Luis was hopeful that a more inclusive community was possible. 
Other participants discussed ways they were taking steps to form stronger connections with other FSL councils. Christina noted that Kappa Beta "encourage[s] a lot of collaboration between different orgs, whether it's another MGC organization or NPHC, and we're trying really hard to reach out to traditionals as well." Omi was excited at the prospect of an upcoming philanthropy collaboration she coordinated with an NPC sorority and an IFC fraternity on campus: "We never hang out with traditionals; no one really hangs out with the traditionals. And I think it's going to be great for us to actually interact with them." This was a small step toward collaboration since it really only involved representatives from the chapters communicating via e-mail to plan the event: "It's not like physical collaboration where we actually meet-everything is through e-mail." The significance of the event to Omi was not the collaboration that had taken place so far, but that members would be brought together at the event; it would help to get Pi Delta's name out; and it would show that IFC and NPC chapters were willing to work with small chapters. Omi thought: "Maybe that will increase other sororities and fraternities trying to collaborate with us."

\section{Marginalization in the FSL Office}

Recognition of racial disparities among FSL councils, as well as the sense of being less valued as MGC organizations, also made its way into student perceptions of the FSL offices on campus. For instance, Delta noticed a lack of feeling of belonging in the FSL office and said he just "feel[s] odd" being there. The main reason he felt that way was because the majority of the personnel and students that used the areas were also White, and as a result: "It goes back to skin color, you know? It really shouldn't go to that, but I feel out of place."

Similarly, Nine reflected on feelings of marginalization by pointing out a lack of support when it came to NPHC and MGC at Plains. She expressed that the FSL office

doesn't really spend too much time on us in a way. Like we aren't as important I guess as the other bigger organizations. . .. In the Greek Life office when I have to go and meet with people... I just don't feel comfortable seeing everyone else kind of doing their things and seeing people in their organizations. 
I feel like I'm not their equal because I'm in a different organization. So that's a place I definitely don't feel comfortable in.

Despite the fact that Nine is a chapter president, she was not very familiar with the professional staff in FSL. She explained that none of the staff members were from MGC organizations, but that "there should be." Nine explained that this was important because "our Greek culture is a lot different than IFC and [NPC].... So I think it would just be easier if we had someone that understood a little bit more."

Confusion regarding the role of the FSL office and the extent to which they supported the sororities and fraternities was a common theme across participants. For example, Karla did not know if the FSL office helped her sorority in any way. She had never personally interacted with professional FSL staff and would not even recognize them if she saw them. Understandably, it can be difficult for all chapter members to be familiar with FSL professionals. While Omi was pretty new to the MGC on campus at Clearview University, from her understanding, a member of the FSL professional staff comes to council meetings "maybe once or twice a semester." Omi thought "it would be nice" to have staff that was more involved in MGC:

I don't even know if we have an advisor. ... But whoever our advisor is ... if our advisor came to those meetings once every other week or twice a month or something, I feel they would be able to push us to attend more events that are hosted maybe by traditional ones ... and get our names out there. But it's like they don't even try.

Juan thought the MGC's lack of recognition within the campus stemmed from a lack of understanding regarding the purpose of multicultural sororities and fraternities: "I don't think they really understand the whole idea of creating your own space and taking that a step further and making it not just a club, but making it a Greek organization. That requires a lot more dedication." Juan thought the FSL office played a role in that lack of education. He noted that the FSL office showed a presentation to incoming freshmen: "And it's super in-depth about [NPC] and IFC organizations, and at the very end it's like oh we also have Multicultural Greek Council and National PanHellenic Council." 
Several other participants specifically reflected on the lack of attention multicultural and NPHC sororities and fraternities received during campus orientation. As a member of the Plains orientation team, Davina sat through the FSL presentation, noting: "Out of all 30 slides maybe 2 to 5 were about MGC and NPHC councils. And they didn't really explain what it is." Seeing how short the sections on MGC and NPHC organizations were made Davina "kind of mad that they spent so little time" on them. Since she knew they would be presenting this information to new students, she asked the presenters several questions to see how they would respond:

Anytime I would ask them a question they would be like "We don't know, but you can look at their website." OK, that's fine but do you think somebody's going to take the time to look at a website when they're in front of you wanting to know an answer?

Davina thought that since there were four presenters (all from IFC or NPC chapters), it would make sense to have one representative from each council. She and her sorority's president suggested the option to orientation, but were told: "Students that present this presentation over the summer get paid to do this. And so it turned out they don't have funding to have someone from the MGC or the NPHC councils to present over the summer." Davina thought if it were possible to have presenters who were more knowledgeable about the organizations it would "help a lot."

Nine also believed the lack of awareness of multicultural sororities and fraternities stemmed from the FSL office: "They put a lot of emphasis on IFC and [NPC], which makes sense. They have like 10 times more chapters than we do. But... chapters are dying because they don't have enough members. ... Lots of people are like, 'If I would've known about you guys, I wouldn't have rushed."' Because the intake process for NPC sororities occurs in the week before school starts, so it was difficult to prevent that from happening.

Luis described the lack of emphasis on MGC chapters, which also extended beyond orientation:

It always feels like you have IFC and [NPC] and then very, very distant at a minimal scale you have MGC and NPHC.... When 
there's meetings with Greek advisors [and they say], "Our Greeks are going to have such and such thing," they usually mean IFC and [NPC] chapters.... I'm pretty sure if both MGC and NPHC were to die off, the rest of the fraternities and sororities on campus wouldn't even notice.

\section{Recognizing Multicultural Greek Organizations}

Several of the participants from Plains University and Clearview University explained that the FSL offices attempted to be inclusive, but their approaches were often ineffective. For instance, Participant01 said the Latinx/a/o sororities and fraternities were invited to an FSL open house event, but being part of the event was problematic because Pi Delta, as well as the other multicultural chapters, do not have houses. So instead, they "had a poster presentation kind of thing and tabling." When the house tours began, the staff told them, "You guys can go."

Fernando expressed frustration with a similar event at Plains where high school students came to campus to learn about FSL. While he thought the attempt to include MGC was nice,

It isn't a way to highlight our council. . . . It's hosted at the houses and stuff, so when it comes to the Multicultural Greeks, they just kind of set up on a lawn, and that's about it for them. So it's kind of unfair. ... There aren't any Multicultural Greeks that have a house.

One primary way several of the participants thought they were shown they were valued was by being provided a campus office space. For instance, Luis, Juan, and Delta all identified their chapter's office space as a place of belonging. Juan explained that since his fraternity does not have a house, they "use it essentially like a house." Juan thought that having the office space "increases a sense of belonging. I think it really confirms our presence on campus as well."

\section{Discussion and implications}

Findings from this study point to a number of ways that race, racism, power, and oppression were prevalent in the experiences of Latina/o 
sorority and fraternity members within the FSL community, which ultimately affected their sense of belonging within FSL. Strayhorn's (2012) definition of sense of belonging includes "the experience of mattering or feeling cared about, accepted, respected, valued by, and important to the group" (p. 3). Similar to Ray's (2013) findings on the experiences of NPHC members, Latina/o sorority and fraternity members were rarely recognized by members of the FSL community beyond MGC and NPHC chapters. This aspect of the behavioral dimension (Hurtado et al., 2012) contributed to systemic patterns of oppression, whereby organizations created for People of Color were made invisible.

Participants' lack of a sense of belonging within the FSL community was largely affected by their perceptions of racial/ethnic dynamics within FSL. Hiraldo's (2010) description of the third tenet of CRT asserts the right of exclusion as an extension of Whiteness as property. This tenet was reflected through the compositional dimension (Hurtado et al., 2012) of IFC and NPC chapters and was one way participants recognized racial exclusion within FSL communities at both Plains and Clearview. In addition to observing the lack of compositional diversity of FSL councils, many of the participants also asserted that their racial or ethnic identities would not be valued within IFC or NPC communitiesevidence of the psychological dimension (Hurtado et al., 2012) of the FSL climate. The behavioral dimension (Hurtado et al., 2012) influenced these perceptions through participants' firsthand experiences with IFC and NPC members and their stories - such as the one shared by Omi regarding the football player being asked to leave a fraternity houseof how other People of Color experienced racism or discrimination in these organizations.

Furthermore, LatCrit was a useful framework in centering the participants' Latina/o identities in relation to their MGC membership and relationship to the rest of the FSL community. For instance, language influenced Lori's experience as she asserted that if she were in an NPC sorority, she would not feel comfortable bringing her mom there because she spoke only Spanish and because "they would judge her." Another example of participants' Latina/o identities coming into play was Luis's discussion on being invited to a fraternity to cosponsor a "burrito bash." As emphasized in CRT, participants did not recognize these stories and experiences as "isolated acts," but rather as "deeply ingrained" (Ladson-Billings \& Tate, 1995, p. 52) aspects of IFC and NPC culture. 
Participants also challenged the idea of "equal opportunity for all," which underscores the fifth tenet of CRT (Hiraldo, 2010, p. 56). While Latinx/a/o sororities and fraternities were not excluded from membership in the FSL community, NPC and IFC chapters garnered most of the focus and resources from the FSL office and campus community, which was evident in orientation sessions where MGC and NPHC chapters were given little attention compared to IFC and NPC chapters. As a result, institutions were able to appear as though they served Students of Color by simply offering culturally based sororities and fraternities, yet the behavioral reality of these FSL offices was that they did not support MGC organizations in the same ways that they supported IFC and NPC organizations. Most of the participants did not even know the name of a campus FSL professional staff member, which reflected the lack of resources these chapters received.

These findings carry a number of implications for FSL communities. First and foremost, FSL professional staff must engage in critical self-reflection on the ways practices and policies perpetuate systemic oppression within the FSL community. Importantly, participants described feeling marginalized within the FSL office, being treated as lesser than NPC and IFC chapter members, and experiencing a lack of attention to their chapters from FSL professionals. The fact that most of the participants did not know the name of a professional FSL staff member on campusincluding Nine, who was a chapter president, and Omi, who served as an officer in MGC - showed that staff on these campuses were not actively engaged with these chapters. FSL professionals should consider how ignoring MGC or NPHC chapters serves to further oppress these groups. The need for time and attention from professional staff highlights an important consideration in terms of equity within the FSL system. The fifth tenet of CRT addresses the pretense of "equal opportunity for all" (Hiraldo, 2010, p. 56). Institutions support bringing MGC organizations to campus, which provides an illusion of equal opportunity, yet the lack of resources given to these chapters underscores the reality of inequality and acts as an indicator of how undervalued they truly are within the greater FSL community and campus environment.

FSL professionals must recenter their approach using a lens of equity instead of equality. As opposed to equality, increased equity in FSL communities does not mean all chapters will engage in the same activities or will be given the same forms of support. For instance, several 
participants discussed the lack of information regarding MGC and NPHC that incoming students were given during campus orientation, in contrast to the time spent discussing IFC and NPC. While most incoming college students may be more familiar with NPC and IFC organizations, as compared to MGC and NPHC organizations, many students may not even know that MGC or NPHC organizations exist, much less why. Thus, institutions should consider the reverse-allocating more time and resources to educating the campus community about these organizations as opposed to NPC and IFC organizations. Furthermore, campus leaders must consider whether orientation session presenters represent diverse identities and are knowledgeable regarding all councils.

In addition, participants emphasized that how multicultural organizations operate can be very different from how NPC and IFC organizations do, including abiding by different national guidelines. The fact that these organizations often do not have houses is another large distinction between the groups. Rather than striving for equality by incorporating MGC chapters in structures and events that were designed for IFC and NPC chapters, recognizing the unique nature of MGC organizations and approaching support with this in mind would be much more helpful. For instance, rather than have MGC chapters attend a house tour night, institutions could feature a separate event highlighting the development and unique culture of MGC organizations. Like NPHC organizations, MGC organizations were formed to serve Students of Color and other marginalized populations in ways that NPC and IFC organizations do not. Rather than silencing this history through overly brief discussions on MGC, FSL staff should give voice to these groups by ensuring that documents and promotional materials center their rich history and purpose.

Finally, FSL professional staff can take measures to enhance community and collaboration among chapters. All participants described their organizations as being different worlds from IFC and NPC organizations. And while there are a number of ways these organizations are different, they also share commonalities, such as emblems (i.e., colors, mascots, letters), the bonds of sisterhood and brotherhood, and a commitment to philanthropy, that form the foundation of FSL. The differences the participants perceived between MGC chapters and IFC and NPC chapters, however, overshadowed these commonalities. This strongly highlights the need for programming centered on cross-organizational education. Furthermore, the prevalence of racially charged incidents stemming from 
the behavior of NPC and IFC chapter members calls attention to the need for intentional conversations on racism, power, and privilege in addition to programming that encourages interactions across difference. Creating systemic change within FSL communities will not be successful without engaging all members of the community.

\section{Conclusion}

Similar to other studies focused on the experiences of members of Latinx/a/o sororities and fraternities (Atkinson et al., 2010; DelgadoGuerrero \& Gloria, 2013; Guardia \& Evans, 2008), sorority and fraternity membership for the participants in this study played a positive role in their overall college experience; however, the sense of belonging that individuals experienced within their chapters did not necessarily carry over in relation to the greater FSL community. While there are some ways that chapters are recognized and made visible on campus, FSL professionals and student members must critically interrogate the status quo and introduce systemic changes that FSL needs to make in order to cultivate more equitable communities.

\section{References}

Asel, A. M., Seifert, T. A., \& Pascarella, E. T. (2009). The effects of fraternity/sorority membership on college experiences and outcomes: A portrait of complexity. Oracle: The Research Journal of the Association of Fraternity/Sorority Advisors, 4(2), 1-15.

Atkinson, E., Dean, L. A., \& Espino, M. M. (2010). Leadership outcomes based on membership in Multicultural Greek Council (MGC) organizations. Oracle: The Research Journal of the Association of Fraternity/Sorority Advisors, 5(2), 34-48.

Bourke, B. (2010). Experiences of Black students in multiple cultural spaces at a predominantly White institution. Journal of Diversity in Higher Education, 3, 126-135. doi:10.1037/a0019025

Cabrera, N. L. (2014). Exposing Whiteness in higher education: White male college students minimizing racism, claiming victimization, and recreating White supremacy. Race, Ethnicity and Education, 17, 30-55. doi:10.1080/13613324.201 2.725040

Clark-Ibáñez, M. (2004). Framing the social world with photoelicitation interviews. American Behavioral Scientist, 47, 1507-1527. doi:10.1177/0002764204266236 
Council for the Advancement of Standards in Higher Education. (2015). CAS selfassessment guide for fraternity and sorority advising programs. Washington, DC: Author.

Delgado Bernal, D. (2002). Critical Race Theory, Latino Critical Theory, and critical raced-gendered epistemologies: Recognizing Students of Color as holders and creators of knowledge. Qualitative Inquiry, 8, 105-126.

Delgado-Guerrero, M., \& Gloria, A. M. (2013). La importancia de la hermandad Latina: Examining the psychosociocultural influences of Latina-based sororities on academic persistence decisions. Journal of College Student Development, 54, 361-378. doi:10.1353/csd.2013.0067

Denson, N., \& Chang, M. J. (2009). Racial diversity matters: The impact of diversityrelated student engagement and institutional context. American Educational Research Journal, 46, 322-353. doi:10.3102/0002831208323278

Garcia, C. E. (2017). Latinx college student sense of belonging: The role of campus subcultures (Doctoral dissertation). Retrieved from ProQuest Dissertations and Theses database. (ProQuest No. 10271563)

Gonzalez, K. P. (2002). Campus culture and the experiences of Chicano students in a predominantly White university. Urban Education, 37, 193-218. doi:10.1177/0042085902372003

Guardia, J. R., \& Evans, N. J. (2008). Factors influencing the ethnic identity development of Latino fraternity members at a Hispanic serving institution. Journal of College Student Development, 49, 163-181. doi:10.1353/csd.0.0011

Harris Combs, B., Stewart, T. L., \& Sonnett, J. (2017). People like us: Dominanceoriented racial affiliation preferences and the White Greek System on a Southern U.S. campus. Sociological Spectrum, 37, 27-47. doi:10.1080/02732173.2016.1264 281

Hiraldo, P. (2010). The role of Critical Race Theory in higher education. The Vermont Connection, 31(Article 7), 53-59. Retrieved from http://scholarworks.uvm.edu/ tvc/vol31/iss1/7

Hughey, M. W. (2009). Rushing the wall, crossing the sands: Cross-racial membership in U.S. college fraternities and sororities. In C. L. Torbenson \& G. S. Parks, (Eds.), Brothers and sisters: Diversity in college fraternities and sororities (pp. 237-276). Cranbury, NJ: Associated University Presses.

Hurtado, S., Alvarez, C. L., Guillermo-Wann, C., Cuellar, M., \& Arellano, L. (2012). A model for diverse learning environments: The scholarship on creating and assessing conditions for student success. In J. C. Smart \& M. B. Paulsen (Eds.), Higher education: Handbook of theory and research, 27, 41-122. doi:10.1007/97894-007-2950-6_2

Ladson-Billings, G. (1998). What is Critical Race Theory and what is it doing in a nice field like education? International Journal of Qualitative Studies in Education, 11, 7-24. doi:10.1080/095183998236863

Ladson-Billings, G., \& Tate, W. F., IV. (1995). Toward a Critical Race Theory of education. Teachers College Record, 97, 47-68. 
Martin, G. L., Parker, G., Pascarella, E. T., \& Blechschmidt, S. (2015). Do fraternities and sororities inhibit intercultural competence? Journal of College Student Development 56, 66-72. doi:10.1353/csd.2015.0010

Maxwell, J. A. (2013). Qualitative research design: An interactive approach (3rd ed.). Thousand Oaks, CA: SAGE.

Merriam, S. B. (2001). Qualitative research and case study applications in education: Revised and expanded from case study research in education. San Francisco, CA: Jossey-Bass.

Merriam, S. B., \& Tisdell, E. J. (2016). Qualitative research: A guide to design and implementation (4th ed.). San Francisco, CA: Jossey-Bass.

Miles, M. B., Huberman, A. M., \& Saldaña, J. (2014). Qualitative data analysis: A methods sourcebook (3rd ed.). Thousand Oaks, CA: SAGE.

Muñoz, S. M., \& Guardia, J. R. (2009). Nuestra historia y futuro [Our history and future]: Latino/a fraternities and sororities. In C. L. Torbenson \& G. S. Parks (Eds.), Brothers and sisters: Diversity in college fraternities and sororities. Madison, NJ: Fairleigh Dickinson University Press.

Museus, S. D. (2008). Focusing on institutional fabric: Using campus culture assessments to enhance cross-cultural engagement. In S. R. Harper (Ed.), Creating inclusive environments for cross-cultural learning and engagement in higher education. Washington, DC: National Association of Student Personnel Administrators.

Museus, S. D., \& Quaye, S. J. (2009). Toward an intercultural perspective of racial and ethnic minority college student persistence. The Review of Higher Education, 33, 67-94. doi:10.1353/rhe.0.0107

National Panhellenic Conference. (2014). NPC position statement on all-Greek councils. Retrieved from http://www.npcwomen.org/wp-content/uploads/ sites/2037/2017/08/Position-Statement-All-Greek-Councils.pdf

North American Interfraternity Conference. (2017). About Interfraternity Council (IFC). Retrieved from http://nicfraternity.org/about-interfraternity-council-ifc

Owens Patton, T. (2008). Jim Crow on fraternity row. Visual Communication Quarterly, 15, 150-168. doi:10.1080/15551390802235503

Park, J. (2008). Race and the Greek system in the 21st century: Centering the voices of Asian American women. NASPA Journal, 45, 103-132. doi:10.2202/1949-6605.1909

Park, J. J. (2014). Clubs and the campus racial climate: Student organizations and interracial friendship in college. Journal of College Student Development, 55, 641-660. doi:10.1353/csd.2014.0076

Ray, R. (2013). Fraternity life at predominantly White universities in the US: The saliency of race. Ethnic and Racial Studies, 36, 320-336. doi:10.1080/01419870.2 012.676201

Ray, R., \& Rosow, J. A. (2012). The two different worlds of Black and White fraternity men: Visibility and accountability as mechanisms of privilege. Journal of Contemporary Ethnography, 41, 66-94. doi:10.1177/0891241611431700 
Ross, L. C., Jr. (2000). The divine nine: The history of African American fraternities and sororities. New York, NY: Kensington Publishing Corp.

Saldaña, J. (2016). The coding manual for qualitative researchers (3rd ed.). Thousand Oaks, CA: SAGE.

Solorzano, D. G., \& Yosso, T. J. (2001). Critical Race and LatCrit theory and method: Counter-storytelling. International Journal of Qualitative Studies in Education, 14, 471-495.

Stake, R. E. (2006). Multiple case study analysis. New York, NY: Guilford Press.

Strayhorn, T. L. (2012). College students' sense of belonging: A key to educational success for all students. New York, NY: Routledge.

Torbenson, C. L. (2012). The origin and evolution of college fraternities and sororities. In T. L. Brown, G. S. Parks, \& C. M. Phillips (Eds.), African American fraternities and sororities: The legacy and the vision (2nd ed., pp. 33-61). Lexington: The University Press of Kentucky. 